\title{
Azithromycin Misuse During the COVID-19 Pandemic: A Cross-Sectional Study from Jordan
}

\author{
Suzanne MA Abdelmalek (D), Abdelrahman Mousa $\mathbb{D}$ \\ Department of Pharmacology and Biomedical Sciences, Faculty of Pharmacy and Medical Sciences, University of Petra, Amman, Jordan
}

Correspondence: Suzanne MA Abdelmalek, Department of Pharmacology and Biomedical Sciences, Faculty of Pharmacy and Medical Sciences, University of Petra, P.O. Box 96I343, Amman, II 196, Jordan, Tel +962 6-6799555, ext. 83 I0, Fax +962 6-57I5570, Email sabdelmalek@uop.edu.jo

Objective: Since coronavirus disease 2019 (COVID-19) became a global pandemic, repurposing known drugs was the quickest way to combat the disease. The initial screening revealed that azithromycin (AZM) might have potential against COVID-19. Although clinical trials did not prove such efficacy, many countries have put AZM within their guidelines for treating COVID-19. Therefore, the present study was designed to assess the misuse of AZM in Jordan during the COVID-19 pandemic.

Methods and Results: A cross-sectional study was conducted among community pharmacies in Jordan from March 27 to May 8 , 2021, and 184 pharmacies data were collected from the Google forms. During COVID-19, 42.9\% of pharmacies sold more than 20 packs of prescribed AZM per month compared to $46.7 \%$ of pharmacies used to sell 0-5 packs AZM prescriptions per month before the pandemic. During COVID-19, pharmacists significantly dispensed AZM with and without prescriptions 107\% and $127 \%$, respectively, more than before the pandemic $(\mathrm{p}<0.0001)$. Overall, pharmacists stocked 121\% more AZM packs during COVID19 than before the pandemic $(\mathrm{p}<0.0001)$. Additionally, most pharmacists $(59.7 \%)$ believed that AZM could cure COVID-19 patients. However, using multinomial logistic regression analysis, low-experienced pharmacists were unsure if AZM could positively affect COVID-19 patients ( $\mathrm{p}<0.05, \mathrm{OR}=3.76,95 \% \mathrm{CI}=1.23-11.52)$. Furthermore, low-experienced pharmacists believed that increased use of AZM for the treatment of viral infections could lead to negative consequences $(\mathrm{p}<0.001, \mathrm{OR}=0.161,95 \% \mathrm{CI}$ $0.063-0.414)$.

Conclusion: This study demonstrated that AZM is misused by physicians, pharmacists, and the public in Jordan. Since AZM efficacy on SARS-CoV-2 is scarce, there is a need for new guidelines by governmental health authorities to implement strict enforcement of AZM dispensing during COVID-19 to avoid negative consequences of bacterial resistance.

Keywords: azithromycin, bacterial resistance, COVID-19, Jordan, misuse, prescription, sales, social media

\section{Introduction}

Coronavirus disease 2019 (COVID-19), caused by Severe Acute Respiratory Syndrome Coronavirus 2 (SARS-CoV-2), was first identified as an outbreak of respiratory illness in Wuhan City, China, in 2019. ${ }^{1}$ Then, in March 2020, the World Health Organization (WHO) declared COVID-19 a global pandemic. ${ }^{2}$ Since then, SARS-CoV-2 has caused worldwide fear because the infection spread quickly between countries and the clinical course ranged from mild to severe inflammatory disease resulting in multi-organ failure and death. ${ }^{3,4}$ Due to that, efforts for repurposing known drugs were the quickest way to help combat the disease. After screening FDA-approved chemical library, a group from France demonstrated that Azithromycin (AZM) exhibited the highest in vitro anti-SARS-CoV-2 activity. ${ }^{5}$

AZM is a second-generation, broad-spectrum, synthetic macrolide antibiotic that inhibits protein synthesis. ${ }^{6}$ However, it has been shown that AZM has anti-SARS-CoV-2 activities, ${ }^{5,7,8}$ as well as anti-inflammatory properties, mainly by inhibiting dysregulated production of proinflammatory cytokines. ${ }^{8,9}$ Furthermore, AZM has been used for treating several previous SARS and Middle East Respiratory syndrome diseases. For example, AZM was associated with improved survival rate and time to discontinue mechanical ventilation in SARS. ${ }^{10,11}$ Although there was no clinical evidence, AZM was listed in many countries as part of the COVID-19 treatment protocol. ${ }^{12}$ This led to the public misinformation gained from social media that AZM can cure COVID-19. ${ }^{13}$ 
During the second wave of the pandemic (September 2020 and until the study period of this work), Jordan got a very high rate of COVID-19 cases with a daily mortality rate of 2.6/100,000, reaching an overall of $\sim 700,000$ positive COVID-19 cases and 10,000 deaths. ${ }^{14}$ Because of the high rate of COVID-19 cases, public misinformation about AZM and COVID-19, and since buying antibiotics is not strict with prescriptions in Jordan, ${ }^{15,16}$ many started buying AZM from pharmacies without or with a prescription. Therefore, this study aimed to determine a) if AZM has been misused in Jordan during the COVID-19 pandemic; b) whether pharmacists were dispensing it without a prescription; and c) if physicians were increasingly prescribing it during the pandemic. All in all, the main concern was that AZM resistance would emerge from such misuse.

\section{Materials and Methods}

\section{Study Setting and Sample Size Calculation}

This cross-sectional study was conducted among community pharmacies in Jordan from March 27 to May 8, 2021. Beforehand, the Institutional Ethics Review Board at the University of Petra approved the study protocol (Q1/11/2021). Then, using a Google Form with written consent for participation in the study, the survey link was distributed to pharmacies on social media. The online message included an anonymous and confidentiality statement; therefore, filling out the questionnaire meant they accepted to enroll in the study.

According to the latest Jordan Pharmacists Association data, there are 2801 pharmacies in Jordan. Therefore, for sufficient statistical analysis, the sample size was calculated to be 184 based on the number of pharmacies, a confidence level of $95 \%$, a margin of error of $\pm 7 \%$, and a $50 \%$ response distribution rate. ${ }^{17}$

\section{Questionnaire and Data Collection}

A short questionnaire of 14 questions was designed and distributed online to community pharmacies (Supplementary Material).${ }^{18}$ Four questions were related to the person answering the questionnaire, such as age, gender, and if the person was a practicing pharmacist and years of experience in the field. The rest ten questions were on: AZM dispensing with or without prescription; AZM storage by pharmacies in Jordan before and during the COVID-19 pandemic; the pharmacist's belief that AZM could have a positive effect on COVID-19; and if AZM use for viral infections has negative consequences. Data were collected online via a self-reported questionnaire.

\section{Data Analysis}

Data were exported from the Google forms to Microsoft Excel, then transferred to SPSS version 25 for statistical analysis. Data were categorized and recorded in frequencies or values. Chi-square analysis was performed to test for significant association of single variable, whereas multinomial logistic regression was applied to test for independent variables with covariate variable with the calculation of odds ratio (OR) and 95\% confidence interval (95\%). A 2-sided paired-test was applied when appropriate, and one-way ANOVA was applied when testing for more than two group levels. A p-value of 0.05 was considered significant.

\section{Results}

One hundred eighty-four pharmacies responded to the questionnaire. Most of the responders (54.9\%) were female pharmacists, between $22-29$ years of age (48.4\%), and had 0-5 years of experience (48.9\%) (Table 1). Besides, 95.7\% of the responders were practicing pharmacists. Therefore, the data from the non-practicing pharmacists were excluded for two questions related to AZM treatment for COVID-19 and knowledge of negative consequences.

Before COVID-19, 46.7\% of pharmacies used to sell 0-5 packs AZM prescriptions per month. During COVID-19, however, $42.9 \%$ of pharmacies sold more than 20 packs of prescribed AZM per month (Figure 1A). During COVID-19, pharmacists significantly dispensed AZM with and without prescriptions $107 \%$ and $127 \%$, respectively, more than before the pandemic $(\mathrm{p}<0.0001)$. However, during the COVID-19 pandemic, AZM dispensing without or with prescription was not significantly different $(9.5 \%, \mathrm{p}>0.05)$ (Figure $1 \mathrm{~B})$. 
Table I Demography of the Pharmacists and Their Experience

\begin{tabular}{|l|l|l|c|}
\hline Parameter/Question & Number & Percentage (\%) & P value \\
\hline Gender & & & \\
Male & 83 & 45.1 & n.s. \\
Female & 101 & 54.9 & \\
\hline Age Group (years) & & & \\
$22-30$ & 89 & 48.4 & $<0.001$ \\
$31-40$ & 33 & 17.9 & \\
Over 40 & 62 & 33.7 & \\
\hline Are you a practicing pharmacist? & & & \\
Yes & 176 & 95.7 & \\
No & 8 & 4.3 & \\
\hline How long have been working as a pharmacist? & & & \\
0-5 years & 90 & 48.9 & \\
6-10 years & 27 & 14.7 & \\
Over I0 years & 67 & 36.4 & \\
\hline
\end{tabular}

Abbreviation: n.s., not significant.

In parallel to the above, $54.9 \%$ of pharmacies used to stock 5-10 packs of AZM, whereas during the COVID-19 pandemic, $44 \%$ of pharmacies began stocking more than 40 packs of AZM (Table 2). Overall, pharmacists stocked AZM $121 \%$ higher during COVID-19 than before the pandemic $(\mathrm{p}<0.0001)$ (Table 2). Besides, almost all the pharmacists (94.6\%) realized increased AZM sales during the pandemic, and 92.9\% felt they needed to order more AZM packs.

Pharmacists' beliefs about the role of AZM in COVID-19 treatment varied based on their experience and age (Table 3). Most pharmacists (59.7\%) believed AZM could cure COVID-19 patients. However, the least group who believed in that was the low-experienced pharmacists $(47.6 \%)$ compared to $84.6 \%$ and $65.2 \%$ for $6-10$ and more than ten years experienced pharmacists, respectively (Table 3). Furthermore, using multinomial logistic regression analysis, lowexperienced pharmacists were unsure if AZM could have a positive effect on COVID-19 patients $(p<0.05$, OR=3.76, 95\% CI $=1.23-11.52$ ) (Table 4). Besides, although more experienced pharmacists (more than ten years) had a trend of stocking more AZM than low experienced pharmacists ( $0-5$ years) before the pandemic ( $p>0.05)$, this difference became significant during the COVID-19 pandemic $(\mathrm{p}<0.001)$. On the other hand, there was no difference in stocking AZM between highly experienced and middle (6 - 10 years) experienced pharmacists before or during the pandemic.

Notably, 52.2\% of the pharmacists believed that using AZM to treat viral infections could have negative consequences, and the majority (65.5\%) of these were low-experienced pharmacists (Table 5). Furthermore, low-experienced pharmacists' belief that increased use of AZM for the treatment of viral infections could lead to negative consequences was statistically significant $(\mathrm{p}<0.001, \mathrm{OR}=0.161,95 \%$ CI $0.063-0.414)$ (Table 6).

\section{Discussion}

Between March to May 2021, Jordan experienced the third wave of COVID-19, and cases were between 2000-9000/ day. ${ }^{19}$ Therefore, the study period should represent a peak of pandemic activity. During this period, the study showed a significant increase in stocking and sales of AZM with or without prescription by 184 community pharmacies in Jordan compared to the pre-COVID-19 period. This increased stocking and sales of AZM was likely due to the initial guidelines, including AZM and its possible effectiveness against SARS-CoV-2 infection and sudden surge of patients seeking Medical- or self-care for confirmed or presumptive COVID-19 condition. Furthermore, several studies, including the WHO, reported increased AZM use. ${ }^{20-23}$ In addition, some showed increased use of AZM with hydroxychloroquine since some in vitro studies stated that both drugs would show better inhibitory effects on SARS-CoV-2 infection. 5,21 


\section{A}

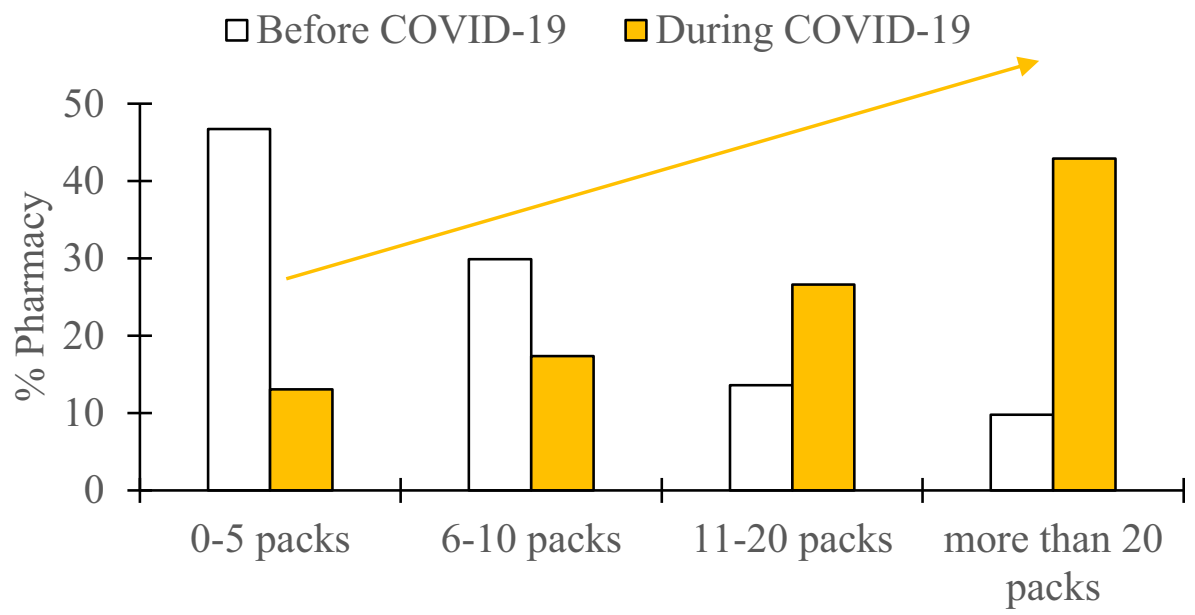

AZM sold with prescription/month

B

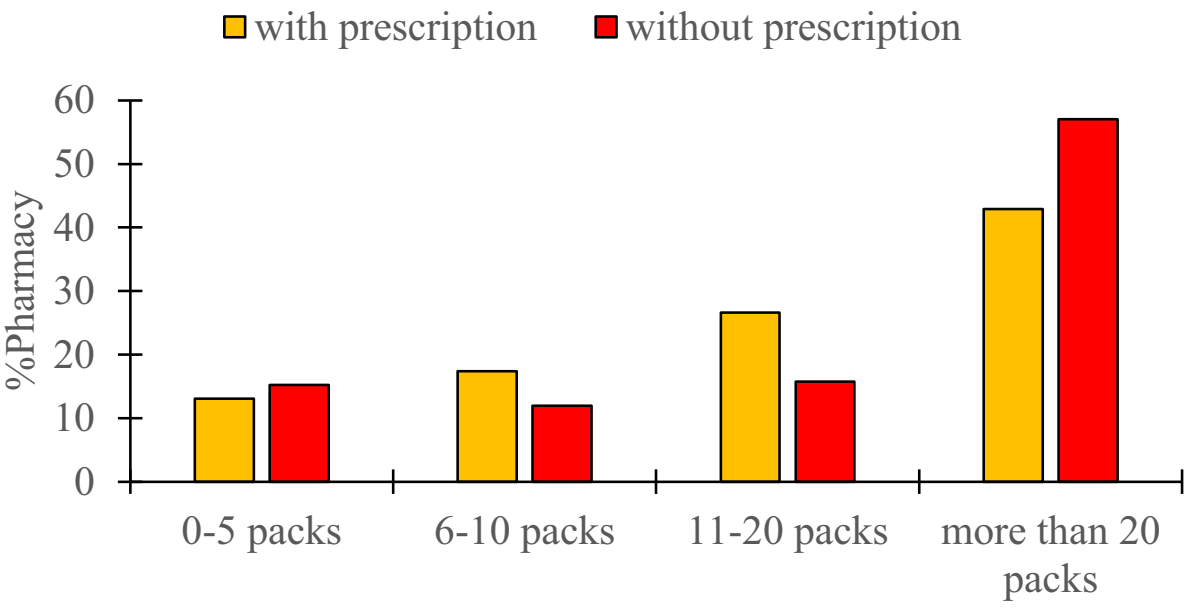

AZM sold during COVID-19/month

Figure I The percentage of pharmacies in Jordan selling AZM per month; (A) with prescription before and during COVID-I9, and (B) without or with prescription during COVID-19. During COVID-19, the number of prescribed AZM packs/per month sold was significantly higher than before the pandemic (see the text for more details). However, in (B), the numbers of AZM packs sold during COVID without or with prescription were not significantly different.

A good number of studies reported high use of antibiotics during COVID-19 on hospitalized and non-hospitalized patients. ${ }^{20-25}$ These uses were partly due to the clinical care guidelines in some countries. However, Goyal et al reported that out of 393 COVID-19 patients in New York, only 5.6\% developed bacteremia without receiving antibiotics. Besides, most of the latter frequency occurred in patients on invasive mechanical ventilation. ${ }^{26}$ Furthermore, in a metaanalysis of bacterial infection in hospitalized patients, only $8 \%$ of all patients were found to have coinfections or secondary bacterial infections. ${ }^{27}$ Since most of these infections were nosocomial infections, the chance of developing secondary bacterial infection for non-hospitalized COVID-19 patients has been considered rare ${ }^{28}$ Besides, since the double-blind placebo-controlled studies of AZM with or without hydroxychloroquine for treating COVID-19 did not reveal sufficient efficacy results, there is no scientific evidence for physicians to prescribe AZM for non-hospitalized COVID-19 patients. $^{29,30}$

In the present study, most pharmacists (59.7\%) believed that AZM could treat COVID-19. A recent survey in Jordan showed that most pharmacists (55.8\%) get their source of information in response to COVID-19 from social media. In 
Table 2 AZM Stocking and Observation of Sales Before and During COVID-I 9 Pandemic

\begin{tabular}{|l|l|l|}
\hline Question & Number & $\begin{array}{l}\text { Percentage } \\
\text { (\%) }\end{array}$ \\
\hline $\begin{array}{l}\text { Before the pandemic, how many packs of AZM did you use to stock at your } \\
\text { pharmacy? }\end{array}$ & & \\
$5-10$ & $10 I$ & 54.9 \\
II-20 & 39 & 21.2 \\
2 I-40 & 26 & 14.1 \\
More than 40 & 18 & 9.8 \\
\hline During the pandemic, how many packs of AZM are you stocking at your & & \\
Pharmacy? & & \\
$5-10$ & 16 & 8.7 \\
II-20 & 26 & 14.1 \\
2 I-40 & $6 I$ & 33.2 \\
More than 40 & $8 \mathrm{I}$ & 44 \\
\hline Have you realized an increase in AZM sales during the pandemic? & & \\
Yes & 174 & 94.6 \\
No & 0 & 0 \\
Not sure & 10 & 5.4 \\
\hline During the pandemic, have you felt a need to order more AZM packs than & & \\
before? & & \\
Yes & 171 & $92.9 \%$ \\
No & 7 & $3.8 \%$ \\
Not sure & 6 & 3.3 \\
\hline Have you noticed an increase in AZM sales? & 176 & 95.7 \\
Yes & 2 & 1.1 \\
No & 6 & 3.3 \\
\hline Not sure & & \\
\hline
\end{tabular}

Table 3 Do You Believe That Azithromycin Could Have a Positive Effect on COVID-I9 Patients?

\begin{tabular}{|c|c|c|c|c|c|}
\hline \multicolumn{2}{|l|}{ Variable } & \multicolumn{3}{|l|}{ Response } & \multirow[t]{2}{*}{ P value* } \\
\hline & & \multirow{2}{*}{$\begin{array}{l}\text { Yes } \\
4 \mathrm{I}(49.8 \%)\end{array}$} & \multirow{2}{*}{$\begin{array}{l}\text { Not sure } \\
24(28.9 \%)\end{array}$} & \multirow{2}{*}{$\begin{array}{l}\text { No } \\
18(21.7 \%)\end{array}$} & \\
\hline Age group & $22-30$ & & & & $<0.05$ \\
\hline & $30-40$ & 25 (75.8\%) & 3 (9.1\%) & 5 (I5.2\%) & \\
\hline & Over 40 & 39 (65.0\%) & $6(10.0 \%)$ & I5 (25.0\%) & \\
\hline \multirow[t]{2}{*}{ Gender } & Female & $54(55.7)$ & $23(23.7 \%)$ & $20(20.6)$ & \multirow[t]{2}{*}{ n.s. } \\
\hline & Male & 51 (64.6\%) & $10(12.7 \%)$ & I8 (22.8\%) & \\
\hline \multirow{3}{*}{$\begin{array}{l}\text { Working as } \\
\text { a pharmacist }\end{array}$} & $0-5$ years & 40 (47.6\%) & 26 (31.0\%) & 18 (21.4\%) & \multirow[t]{3}{*}{$<0.001$} \\
\hline & $6-10$ years & 22 (84.6\%) & I (3.8\%) & 3 (1 I.5\%) & \\
\hline & $\begin{array}{l}\text { More than } 10 \\
\text { years }\end{array}$ & $43(65.2 \%)$ & 6 (9.1\%) & I7 (25.8\%) & \\
\hline
\end{tabular}

Note: *Chi square analysis.

Abbreviation: n.s., not significant. 
Table 4 Multinomial Logistic Regression Output of "Do You Believe That Azithromycin Could Have a Positive Effect on COVID-19 Patients?" in Relation to the Pharmacist Experience and Gender as a Covariate

\begin{tabular}{|l|l|l|l|l|}
\hline Output & Variable & OR & $\mathbf{9 5 \%} \mathbf{~ C I}$ & P value \\
\hline \multirow{4}{*}{ Yes } & Gender & 0.910 & $0.425-1.948$ & 0.808 \\
\cline { 2 - 5 } & $0-5$ years' experience & 0.891 & $0.401-1.980$ & 0.777 \\
\cline { 2 - 5 } & $6-10$ years' experience & 2.951 & $0.774-11.257$ & 0.113 \\
\cline { 2 - 5 } & More than 10 years' experience & Ref & Ref & - \\
\hline \multirow{3}{*}{ Not sure } & Gender & 1.794 & $0.657-4.897$ & 0.254 \\
\cline { 2 - 5 } & $0-5$ years' experience & 3.764 & $1.230-11.522$ & 0.020 \\
\cline { 2 - 5 } & $6-10$ years' experience & 0.850 & $0.073-0.914$ & 0.897 \\
\cline { 2 - 5 } & More than 10 years' experience & Ref & Ref & - \\
\hline
\end{tabular}

Note: No, is set as a reference category.

contrast, low percentages get their source of information from either the WHO site $(6.0 \%)$ or scientific journals $(5.2 \%){ }^{31}$ Since social media containing misinformation or myths increased during the COVID pandemic, general people or professionals started to believe in what they read. ${ }^{15}$ One of these myths is that "antibiotics are effective in preventing and treating new coronavirus." Thus, it is not unusual for more than half of pharmacists to believe in that statement.

Furthermore, the present study showed that less experienced pharmacists believed less that AZM could treat COVID19 disease and believed more of the negative consequences of using AZM in viral infections. Such belief led them to stock less AZM in their Pharmacy during the pandemic. These results may suggest that fresh pharmacy graduates have more assurance that antibiotics should not be used for viral infections unless preventing secondary bacterial infection. On the other hand, the more experienced pharmacist may tend to go with the flow and believe what they read on social media over the scientific knowledge gained during studying their degree. ${ }^{15,31,32}$ The latter opens the need for continuous education for pharmacists.

Table 5 Do You Believe That Increased Use of Azithromycin for the Treatment of Viral Infections Could Lead to Negative Consequences?

\begin{tabular}{|c|c|c|c|c|c|}
\hline \multicolumn{2}{|l|}{ Variable } & \multicolumn{3}{|l|}{ Response } & \multirow[t]{2}{*}{ P value* } \\
\hline & & Yes & Not sure & No & \\
\hline \multirow[t]{3}{*}{ Age group } & $22-30$ & 56 (67.5\%) & 19 (22.9\%) & 8 (9.6\%) & \multirow[t]{3}{*}{$<0.05$} \\
\hline & $30-40$ & 16 (48.5\%) & 7 (21.2\%) & $10(30.3 \%)$ & \\
\hline & Over 40 & 20 (33.3\%) & $20(33.3 \%)$ & 20 (33.3\%) & \\
\hline \multirow[t]{2}{*}{ Gender } & Female & $54(55.7)$ & 22 (22.7\%) & $21(21.6)$ & \multirow[t]{2}{*}{ n.s. } \\
\hline & Male & 38 (48.1\%) & 24 (30.4\%) & I7 (2I.7\%) & \\
\hline \multirow{3}{*}{$\begin{array}{l}\text { Working as } \\
\text { a pharmacist }\end{array}$} & $0-5$ years & 55 (65.5\%) & 21 (25.0\%) & $8(9.5 \%)$ & \multirow[t]{3}{*}{$<0.01$} \\
\hline & $6-10$ years & II (42.3\%) & $8(30.8 \%)$ & 7 (26.9\%) & \\
\hline & $\begin{array}{l}\text { More than } 10 \\
\text { years }\end{array}$ & 26 (39.4\%) & 17 (25.8\%) & 23 (34.8\%) & \\
\hline
\end{tabular}

Note: *Chi square analysis.

Abbreviation: n.s., not significant. 
Table 6 Multinomial Logistic Regression Output of "Do You Believe That Increased Use of Azithromycin for the Treatment of Viral Infections Could Lead to Negative Consequences" in Relation to the Pharmacist Experience and Gender as a Covariate

\begin{tabular}{|l|l|l|l|l|}
\hline Output & Variable & OR & $95 \% \mathbf{C l}$ & P value \\
\hline \multirow{4}{*}{ No } & Gender & 1.113 & $0.493-2.515$ & 0.796 \\
\cline { 2 - 5 } & $0-5$ years' experience & 0.161 & $0.063-0.414$ & 0.001 \\
\cline { 2 - 5 } & $6-10$ years' experience & 0.705 & $0.232-2.144$ & 0.538 \\
\cline { 2 - 5 } & More than 10 years' experience & Ref & Ref & - \\
\hline \multirow{3}{*}{ Not sure } & Gender & 0.681 & $0.329-1.410$ & 0.301 \\
\cline { 2 - 5 } & $0-5$ years' experience & 0.627 & $0.281-1.403$ & 0.256 \\
\cline { 2 - 5 } & $6-10$ years' experience & 1.194 & $0.394-3.618$ & 0.754 \\
\cline { 2 - 5 } & More than I0 years' experience & Ref & Ref & - \\
\hline
\end{tabular}

Note: Yes, is set as a reference category.

Since antibiotic misuse has been high for decades, antibiotic resistance has been of significant concern in developing and developed countries. ${ }^{15,16,32-36}$ In Jordan, for instance, $73 \%$ of Cutibacterium acnes isolated from patients with acne were resistant to erythromycin, 59\% to clindamycin, 37\% to doxycycline and tetracycline, and $31 \%$ to trimethoprim/sulfamethoxazole. Additionally, in a study conducted in 2019 (pre-COVID-19 period) on 504 healthy college students in Jordan, the researchers found that $40.4 \%$ of students carried methicillin-resistant Staphylococci isolated from nasal and skin areas. ${ }^{37}$ These isolates were $46 \%$ resistant to cefoxitin, $35 \%$ to erythromycin, $13 \%$ to ciprofloxacin, $12 \%$ to nitrofurantoin, and $10 \%$ to gentamicin, but not to hospital-restricted injection-type antibiotics, amikacin (1.5\%) and vancomycin $(0.5 \%) .{ }^{37}$ These results indicate the consequence of the misuse and overuse of antibiotics in Jordan.

The concern for developing more antibiotic-resistance during the COVID-19 pandemic is expected to be significant since the AZM (and other antibiotics) misuse and overuse is two to three folds higher, as presented herein and in other studies. ${ }^{22,27}$ Therefore, new measures of clinical guidelines on using AZM and other antibiotics for COVID-19 patients in Jordan and other countries are warranted. ${ }^{22,27,36}$ Furthermore, these new measures should be distributed on social media to overcome and balance the false information that the public and the health practitioners are receiving.

The present study has limitations. Firstly, although the number of required pharmacies was statistically sufficient, the sample size may not represent the whole pharmacies in Jordan. Secondly, other antibiotics could also be highly used during the pandemic in Jordan. Thirdly, the study included a few sociodemographic variables, whereby more variables might clarify the outcome better.

In conclusion, this study demonstrated that AZM is misused by physicians, pharmacists, and the public in Jordan. Since AZM efficacy on SARS-CoV-2 is scarce, there is a need for new guidelines by governmental health authorities to implement strict enforcement of AZM dispensing during COVID-19 to avoid negative consequences of bacterial resistance.

\section{Disclosure}

The authors declare no conflicts of interest for this work.

\section{References}

1. Zhu H, Wei L, Niu P. The novel coronavirus outbreak in Wuhan, China. Glob Health Res Policy. 2020;5:6. doi:10.1186/s41256-020-00135-6

2. World Health Organization Regional Office for Europe. Health topics: WHO announces COVID-19 outbreak a pandemic; 2020.Available from: https://www.euro.who.int/en/health-topics/health-emergencies/coronavirus-covid-19/news/news/2020/3/who-announces-covid-19-outbreak-a-pan demic. Accessed November 5, 2021. 
3. Chen N, Zhou M, Dong X, et al. Epidemiological and clinical characteristics of 99 cases of 2019 novel coronavirus pneumonia in Wuhan, China: a descriptive study. Lancet. 2020;395(10223):507-513. doi:10.1016/S0140-6736(20)30211-7

4. Huang C, Wang Y, Li X, et al. Clinical features of patients infected with 2019 novel coronavirus in Wuhan, China. Lancet. 2020;395:497-506. doi:10.1016/S0140-6736(20)30183-5

5. Touret F, Gilles M, Barral K, et al. In vitro screening of a FDA approved chemical library reveals potential inhibitors of SARS-CoV-2 replication. Sci Rep. 2020;10(1):13093. doi:10.1038/s41598-020-70143-6

6. Schönfeld W, Kirst HA. Effects of Macrolide Antibiotics on Ribosome Function. Basel: Birkhäuser Verlag; 2002.

7. Damle B, Vourvahis M, Wang E, et al. Clinical Pharmacology perspectives on the antiviral activity of azithromycin and use in COVID-19. Clin Pharmacol Ther. 2020;108:201-211. doi:10.1002/cpt.1857

8. Gyselinck I, Janssens W, Verhamme P, et al. Rationale for azithromycin in COVID-19: an overview of existing evidence. BMJ Open Resp Res. 2021;8:e00806. doi:10.1136/bmjresp-2020-000806

9. Oliver ME, Hinks TSC. Azithromycin in viral infections. Rev Med Virol. 2021;31(2):e2163. doi:10.1002/rmv.2163

10. Kawamura K, Ichikado K, Takaki M, Eguchi Y, Anan K, Suga M. Adjunctive therapy with azithromycin for moderate and severe acute respiratory distress syndrome: a retrospective, propensity score-matching analysis of prospectively collected data at a single center. Int J Antimicrob Agents. 2018;51(6):918-924. doi:10.1016/j.ijantimicag.2018.02.009

11. Arabi YM, Deeb AM, Al-Hameed F, et al. Macrolides in critically ill patients with Middle East Respiratory Syndrome. Int $J$ Infect Dis. 2019;81:184-190. doi:10.1016/j.ijid.2019.01.041

12. Ali AS, ASattar MA, Karim S, et al. Pharmacological basis for the potential role of Azithromycin and Doxycycline in management of COVID-19. Arab J Chem. 2021;14(3):102983. doi:10.1016/j.arabjc.2020.102983

13. Kim H, Walker D, Dredze M, Sangraula A, Smith MC, Quinn SC. Leveraging volunteer fact checking to identify misinformation about COVID-19 in social media. Harv Kennedy Sch Misinformation Rev. 2020;1(3). doi:10.37016/mr-2020-38

14. Ministry of Health (Jordan). "COVID-19 statistical report". 2021.

15. Almaaytah A, Mukattash TL, Hajaj J. Dispensing of non-prescribed antibiotics in Jordan. Patient Prefer Adherence. 2015;9:1389. doi:10.2147/PPA. S91649

16. Morgan DJ, Okeke IN, Laxminarayan R, Perencevich EN, Weisenberg S. Non-prescription antimicrobial use worldwide: a systematic review. Lancet Infect Dis. 2011;11(9):692-701. doi:10.1016/S1473-3099(11)70054-8

17. RAOSOFT. Sample size calculator 2020. Available from: http://www.raosoft.com/samplesize.html. Accessed March 2, 2020.

18. Awad AI, Aboud EA, Singer AC. Knowledge, attitude and practice towards antibiotic use among the public in Kuwait. PLoS One. 2015;10(2): e0117910. doi:10.1371/journal.pone.0117910

19. Worldometer. Coronavirus statistics: Jordan; 2021.Available from: https://www.worldometers.info/coronavirus/country/jordan/. Accessed May 1, 2021.

20. de Lusignan S, Joy M, Sherlock J, et al. PRINCIPLE trial demonstrates scope for in-pandemic improvement in primary care antibiotic stewardship. medRxiv. 2021. doi:10.1101/2021.02.02.21250902

21. Sulis G, Batomen B, Kotwani A, Pai M, Gandra S. Sales of antibiotics and hydroxychloroquine in India during the COVID-19 epidemic: an interrupted time series analysis. PLoS Med. 2021;18(7):e1003682. doi:10.1371/journal.pmed.1003682

22. Elsayed AA, Darwish SF, Zewail MB, Mohammed M, Saeed H, Rabea H. Antibiotic misuse and compliance with infection control measures during COVID-19 pandemic in community pharmacies in Egypt. Int J Clin Pract. 2021;75(6):e14081. doi:10.1111/ijcp.14081

23. World Health Organization. Clinical Management of COVID-19: Interim Guidance. World Health Organization; 2020.

24. Sharma S, Singh A, Banerjee T. Antibacterial agents used in COVID-19: a systematic review and meta-analysis. Environ Sustain. $2021 ; 4: 503-513$. doi:10.1007/s42398-021-00194-6

25. Kuang L, Liu Y, Wei W, et al. Non-prescription sale of antibiotics and service quality in community pharmacies in Guangzhou, China: a simulated client method. PLoS One. 2020;15(12):e0243555. doi:10.1371/journal.pone.0243555

26. Goyal P, Choi JJ, Pinheiro LC, et al. Clinical characteristics of Covid-19 in New York city. N Engl J Med. 2020;382(24):2372-2374. doi:10.1056/ NEJMc2010419

27. Langford BJ, So M, Raybardhan S, et al. Bacterial co-infection and secondary infection in patients with COVID-19: a living rapid review and meta-analysis. Clin Microbiol Infect. 2020;26(12):1622-1629. doi:10.1016/j.cmi.2020.07.016

28. Chi SY, Kim TO, Park CW, et al. Bacterial pathogens of ventilator associated pneumonia in a tertiary referral hospital. Tuberc Respir Dis. 2012;73:32-37. doi:10.4046/trd.2012.73.1.32

29. Sivapalan P, Suppli Ulrik C, Sophie Lapperre T, et al. Azithromycin and hydroxychloroquine in hospitalised patients with confirmed COVID-19-a randomised double-blinded placebo-controlled trial. Eur Respir J. 2021;59:2100752.

30. Rodrigues C, Freitas-Santos RS, Levi JE, et al. Hydroxychloroquine plus azithromycin early treatment of mild COVID-19 in an outpatient setting: a randomized, double-blinded, placebo-controlled clinical trial evaluating viral clearance. Int J Antimicrob Agents. 2021;58(5):106428. doi:10.1016/ j.ijantimicag.2021.106428

31. Muflih SM, Al-Azzam S, Abuhammad S, Jaradat SK, Karasneh R, Shawaqfeh MS. Pharmacists' experience, competence and perception of telepharmacy technology in response to COVID-19. Int J Clin Pract. 2021;75(7):e14209. doi:10.1111/ijcp.14209

32. Alkhawaja E, Hammadi S, Abdelmalek M, Mahasneh N, Alkhawaja B, Abdelmalek SM. Antibiotic resistant Cutibacterium acnes among acne patients in Jordan: a cross sectional study. BMC Dermatol. 2020;20(1):1-9. doi:10.1186/s12895-020-00108-9

33. Okeke IN, Lamikanra A, Edelman R. Socioeconomic and behavioral factors leading to acquired bacterial resistance to antibiotics in developing countries. Emerg Infect Dis. 1999;5(1):18-27. doi:10.3201/eid0501.990103

34. Malik B, Bhattacharyya S. Antibiotic drug-resistance as a complex system driven by socio-economic growth and antibiotic misuse. Sci Rep. 2019;9:9788. doi:10.1038/s41598-019-46078-y 
35. World Health Organization. Newsroom: antibiotic resistance; 2020. Available from: https://www.who.int/news-room/fact-sheets/detail/antibioticresistance. Accessed November 4, 2021.

36. [No authors listed]. Antimicrobial resistance in the age of COVID-19. Nat Microbiol. 2020;5(6):779. doi:10.1038/s41564-020-0739-4

37. Abdelmalek SMA, Qinna MW, Al-Ejielat R, Collier PJ. Methicillin-Resistant Staphylococci (MRS): carriage and antibiotic resistance patterns in college students. J Community Health. 2022. doi:10.1007/s10900-022-01065-9

\section{Publish your work in this journal}

Infection and Drug Resistance is an international, peer-reviewed open-access journal that focuses on the optimal treatment of infection (bacterial, fungal and viral) and the development and institution of preventive strategies to minimize the development and spread of resistance. The journal is specifically concerned with the epidemiology of antibiotic resistance and the mechanisms of resistance development and diffusion in both hospitals and the community. The manuscript management system is completely online and includes a very quick and fair peer-review system, which is all easy to use. Visit http://www.dovepress.com/testimonials.php to read real quotes from published authors.

Submit your manuscript here: https://www.dovepress.com/infection-and-drug-resistance-journal 